\title{
Driving factors of carbon embodied in China's provincial exports
}

\author{
Youguo Zhang a,b, Zhipeng Tang c,d,* \\ a Institute of Quantitative and Technical Economics, Chinese Academy of Social Sciences, No. 5, Jianguomennei Street, Beijing 100732, China \\ b Center for Environment and Development, Chinese Academy of Social Sciences, Beijing 100732, China \\ c Key Laboratory of Regional Sustainable Development Modeling, Chinese Academy of Sciences, Beijing 100101, China \\ d Institute of Geography Sciences and Natural Resources Research, Chinese Academy of Sciences, Beijing 100101, China
}

\section{A R T I C L E I N F O}

\section{Article history:}

Received 8 February 2015

Received in revised form 29 July 2015

Accepted 4 August 2015

Available online 18 August 2015

\section{JEL classification:}

Q56

R11

R15

C67

Q54

\section{Keywords:}

Embodied carbon emissions

Provincial international export

Driving factors

Multi-regional input-output model

Logarithm mean Divisia index

\begin{abstract}
A B S T R A C T
In this paper, we use the multi-regional input-output model (MRIO) and logarithm mean Divisia index approach to analyze the changes in China's carbon embodied in exports (CEE) at the national and provincial levels. The results indicate that the total CEE and the CEE of 17 provinces, including all eastern provinces, decreased between 2007 and 2010. The largest decrease in total CEE is caused by an input structural effect, which decreases the CEE of most of the provinces. The technique effect arising from changes in provincial carbon intensities causes the second largest decrease in total CEE and it effectively reduces the CEE of most of the provinces, especially the eastern provinces. Changes in the export composition of most of the provinces also decrease the provincial CEE. A change in the provincial distribution of exports decreases the CEE in 11 provinces on the one hand and increases the CEE in 19 provinces on the other hand. A change in export volume increases the CEE of each province and the whole country, but its total effect is evidently lower than the input structural effect and the technique effect.
\end{abstract}

(c) 2015 Elsevier B.V. All rights reserved.

\section{Introduction}

Carbon emissions in China have rapidly increased in the last few decades. China is now one of the largest emitters of global carbon emissions. Its trade volume has also increased rapidly, especially after it joined the World Trade Organization (WTO) in 2001. According to the WTO ${ }^{1}$ database, China currently has the largest volume of trade goods. The growth of China's huge investment is highly correlated with the growth of exports (Liu, 2009), and thus China is now considered the "world's industrial plant." Therefore, fast-growing exports are a strong driving force behind China's economic development and an important factor in its energy-related carbon emissions. A number of studies on carbon emissions in China's trade have been published in recent years. These discussions on trade-related carbon emissions have important policy implications for China in reducing its total emissions. Moreover, understanding the effects of trade on carbon emissions is helpful in

\footnotetext{
* Corresponding author at: Institute of Geographic Sciences and Natural Resources Research, Chinese Academy of Sciences, 11A, Datun Road, Chaoyang District, Beijing 100101, China. Tel.: +861064889529.

E-mail addresses: zhyouguo@cass.org.cn (Y. Zhang), tangzp@igsnrr.ac.cn (Z. Tang).

${ }^{1}$ International Trade and Market Access Data, http://www.wto.org.
}

designing an effective climate change program and reducing the global "carbon leakage" in international trade (Andrew et al., 2009).

Almost all the previous studies focusing on the carbon emissions in trade (CET) of China are based on the input-output (IO) analysis, which calculates both the direct and indirect effects of trade on carbon emissions. The national single-region input-output (SRIO) model for China is the most frequently used IO model in previous studies focusing on the national CET of China (Guan et al., 2008; Lin and Sun, 2010; Minx et al., 2011; Pan et al., 2008; Peters et al., 2007; Wang and Watson, 2007; Weber et al., 2008; Yan and Yang, 2010; Zhang, 2012). The method based on a national SRIO model for calculating carbon emissions embodied in trade is the so-called emissions embodied in bilateral trade (EEBT) approach (Peters, 2008). However, the national SRIO model may significantly overestimate the carbon embodied in exports (CEE) if it uses the competitive imports assumption, which neglects the differences in emissions technologies between imported products and domestic products (Su and Ang, 2013). Further, the SRIO model for a country cannot be used to estimate the impact of the country's imports on carbon emissions in other countries.

To avoid the shortcomings of the national SRIO model and obtain an accurate estimate of the carbon emissions embodied in imports, many previous studies (Ahmed and Wyckoff, 2003; Andrew et al., 2009; 
Atkinson et al., 2011; Li and Hewitt, 2008; Liu et al., 2010; Qi et al., 2014; Shui and Harriss, 2006; Su and Ang, 2011) have adopted the multiregion input-output (MRIO) model, which is based on the noncompetitive imports assumption, for several countries (including China). This model evaluates the effect of international trade on carbon emissions. Several large databases, such as the Global Trade Analysis Project (GTAP) database, have been built in recent years to support the application of the MRIO model.

However, most of the previous studies focusing on the national CET of China neglect the significant regional disparity within China (Guo et al., 2012) and may overestimate the CEE of the country. The reason is that most of the exported products are from the eastern provinces ${ }^{2}$ (the coastal area) of China, the carbon intensities of which are lower than those exported products produced in other areas ( $\mathrm{Su}$ and Ang, 2010, 2014; Weitzela and Ma, 2014). When using the national SRIO model or the MRIO model for several countries (including China) without distinguishing China's regional exports to estimate the CEE of China, we will take the national average carbon intensity of a product as the carbon intensity of the same product produced in the coastal area because both the national SRIO model and the MRIO model for several countries do not distinguish between exports from different regions in China. Thus, the carbon intensities of exported products from the coastal area and also the CEE will be overestimated.

Obviously, research on the regional CET would help to deepen our understanding of the CET of China. To fill the gap, several studies estimate the regional CET of China by using the MRIO model for regions within China. ${ }^{3}$ The 1997 regional and total CEE of China based on a complete MRIO model is reported by Su and Ang (2010, 2014), who use the MRIO model for eight regions (each region is an aggregation of several provinces) within China. Weitzela and Ma (2014) estimate the 2007 provincial and total CEE of China using the provincial MRIO model for China. They find that the CEE obtained using the MRIO model is evidently lower than that estimated using the SRIO model. Feng et al. (2013) trace the 2007 carbon emissions for the interprovincial and international trade of China. Guo et al. (2012) also calculate the provincial and total CEE of China using the 2002 extended provincial IO tables, which do not contain interregional intermediate inputs. Meng et al. (2013) adopt the MRIO tables for eight aggregated regions within China to analyze the carbon emissions embodied in interregional trade in China. The results of these studies show that the regional CEE is evidently different in each region.

Further, to explore how carbon is embodied in China's trade, some studies (e.g., Zhang, 2012) use structural decomposition analysis (SDA) to decompose the historical change in CET of China. SDA, which is based on IO tables, and index decomposition analysis (IDA), which is based on annual sector data, are two frequently used approaches for analyzing changes in energy consumption and related carbon emissions to find policy implications (Su and Ang, 2012). ${ }^{4}$ SDA has also been used to analyze the total carbon emissions of China (e.g., Guan et al., 2008; Peters et al., 2007). Several studies have used SDA to analyze regional resource or environmental problems in China in recent years. ${ }^{5}$ For

\footnotetext{
2 According to China's National Bureau of Statistics (CNBS) (http://www.stats.gov.cn/ tjzs/cjwtjd/), the provinces in China can be categorized into four aggregated regions, namely, the eastern, central, western and northeastern regions. The eastern provinces include Beijing, Tianjin, Hebei, Shanghai, Jiangsu, Zhejiang, Fujian, Shandong, Guangdong and Hainan. The central provinces include Shanxi, Anhui, Jiangxi, Henan, Hubei and Hunan. The western provinces include Inner Mongolia, Guangxi, Chongqing, Sichuan, Guizhou, Yunnan, Tibet, Shanaxi, Gansu, Qinghai, Ningxia and Xinjiang; the northeastern provinces include Liaoning, Jilin and Heilongjiang. The data from CNBS indicate that the eastern provinces contributed more than $90 \%$ of China's exports in recent years.

${ }^{3}$ Given that the national MRIO model is a very powerful tool for economic, energy and environmental analysis, several institutes and researchers (such as China State Information Center, 2005; Liu et al., 2012; Zhang and Qi, 2012) have made huge efforts and progress in compiling MRIO tables for China.

4 Su and Ang (2012) provide the latest comparison between IDA and SDA and also review SDA studies applied to energy and emissions up to 2010.

5 Other methods have also been used to study the regional carbon emissions in China, such as IDA (Zhang et al., 2011) and the econometric method (Meng et al., 2011).
}

instance, Zhang and Lahr (2014) use SDA to decompose the energy consumption in seven regions of China. Feng et al. (2012) use SDA and regional IO tables of China for 2002 and 2007 to study the drivers of regional carbon emissions.

However, studies that analyze the regional CET of China after 2007 are not available. The growth rate of China's exports fell sharply to $-0.9 \%$ and $-13 \%$ in 2008 and 2009, respectively, and then recovered to $27 \%$ in 2010 (Chinese Statistical Yearbook 2014). The global financial crisis that occurred in 2008 had a huge impact on China's exports. The crisis influenced China's exports through a number of channels. First, the crisis significantly decreased the external demand for China's exports because it caused a major economic recession in the main destinations for China's exports (e.g., the United States, the European Union and Japan), which account for at least $50 \%$ of China's exported goods (Gao et al., 2009; Liu, 2009). Second, the crisis affected China's foreign direct investment, the majority of which is used to produce exported products (Zhong and Lin, 2012). Third, the trade barriers and real appreciation of the RMB caused by the crisis could have reduced China's exports (Hu and $\mathrm{Li}, 2010)$. The impacts resulting from the crisis on the exports from different regions are not similar to each other (Zhang and Wei, 2011). These findings imply that the global financial crisis had an important impact on the provincial CEEs of China. Did the crisis change the regional contribution of the CEE of China? What were the changes in the regional CEEs before and after the crisis? What are the driving forces and their contribution to the regional and total CEEs of China in this period?

This paper attempts to answer the above questions and makes two contributions to the literature. First, it estimates the 2010 provincial CEE using the latest 2010 provincial MRIO table for 30 provinces of China. Second, it conducts a decomposition analysis of the historical changes in provincial CEE before and after the global financial crisis (2007-2010) to explore the driving factors for CEE at the provincial level in China in this period. To our knowledge, several studies (e.g., Feng et al., 2013; Guo et al., 2012; Weitzela and Ma, 2014) calculate the provincial CEE in China based on the MRIO model, but they fail to compare the provincial CEE for different years. Further, none of them decompose these changes in China's provincial CEE for different years.

The rest of this paper is arranged as follows. In Section 2, we present the hybrid approach and the EEBT approach for calculating the provincial CEE in China and present the decomposition approach, which combines the MRIO technique and the logarithmic mean Divisia index (LMDI) method to analyze the driving factors of the provincial CEE. Our decomposition method can avoid the shortcomings of classical LMDI, which does not take indirect effects on carbon emissions into account (Hoekstra and Van den Bergh, 2003), and the non-uniqueness problem of SDA (Dietzenbacher and Los, 1998). The data used in the empirical analysis are also described in this section. The results of the empirical analysis for provincial CEE in China are reported in Section 3. We discuss the empirical findings in Section 4. Section 5 concludes the study and presents our policy suggestions for reducing the provincial CEE in China.

\section{Methods}

\subsection{Accounting for CEE with the hybrid approach based on the MRIO model}

Regional CEEs can be calculated using either the MRIO model (details of the standard MRIO model can be found in Miller and Blair, 2009) or the SRIO model, as we mentioned in Section 1. The IO technique for calculating CEE based on the MRIO model at the provincial level is the hybrid approach defined by Su and Ang (2014). The hybrid approach combines the MRIO model at the regional level and the EEBT approach at the national level and thus incorporates the interregional feedback effect of the MRIO approach and the transparence of the EEBT approach (Su and Ang, 2014). 
Our model is based on the non-competitive imports assumption, which is more appropriate for estimating the CEE than the competitive imports assumption (Su and Ang, 2013). Assume there are $k$ regions in a country and the economies of each region consist of $n$ sectors. The total CEE of the country, $q$, can be expressed as

$q=\mathbf{C}^{\mathbf{T}}(\mathbf{I}-\mathbf{A})^{-1} \mathbf{H}\left[\left(\mathbf{U}^{\mathbf{1}}\right)^{\mathbf{T}}, \ldots,\left(\mathbf{U}^{\mathbf{r}}\right)^{\mathbf{T}}, \ldots,\left(\mathbf{U}^{\mathbf{k}}\right)^{\mathbf{T}}\right]^{\mathrm{T}} e$

where $\boldsymbol{C}$ is the $K n \times 1$ direct carbon intensity (DCI) vector, the element of which is the DCI of sector $i$ of region $r, c_{i}^{r}$. Further, $c_{i}^{r}=q_{i}^{r} / x_{i}^{r}$, where $q_{i}^{r}$ represent the direct carbon emissions from sector $i$ of region $r$. $I$ is the $K n \times K n$ identity matrix, and $\boldsymbol{A}$ is the $K n \times K n$ interregion IO coefficient matrix, whose entry $a_{i j}^{r s}$ represents the intermediate input coefficient matrix from sector $i$ of region $r$ to sector $j$ of region $s$. $\boldsymbol{H}$ is a $K n \times K n$ diagonal matrix and its element $h_{i}^{r}$ denotes the share of sector $i$ in the total exports of region $r . \boldsymbol{U}^{\boldsymbol{r}}=\left(u^{r}, \ldots, u^{r}, \ldots, u^{r}\right)^{\boldsymbol{T}}$ is an $n \times 1$ vector, and $u^{r}$ denotes the share of region $r$ in the total exports of the country. $e$ is the total exports of the country. The superscript $T$ denotes transpose.

The total CEE of the country can be rewritten as

$q=f\left(\mathbf{C}^{\mathbf{T}}, \mathbf{L}, \mathbf{H}, \mathbf{U}, e\right)=\mathbf{C}^{\mathrm{T}} \mathbf{L H U} e$

where $\mathbf{L}=(\mathbf{I}-\mathbf{A})^{-1}$ is the $K n \times K n$ interregion Leontief inverse, the element of which is $l_{i j}^{r s} \cdot \mathbf{U}=\left[\left(\mathbf{U}^{\mathbf{1}}\right)^{\mathbf{T}}, \ldots,\left(\mathbf{U}^{\mathbf{r}}\right)^{\mathbf{T}}, \ldots,\left(\mathbf{U}^{\mathbf{k}}\right)^{\mathbf{T}}\right]^{\mathrm{T}}$ is the regional distribution vector of exports.

Further, by using the hybrid approach, the CEE of region $r, q^{r}$, can be expressed as

$q^{r}=\mathbf{C}^{\mathbf{T}} \mathbf{L} \mathbf{H}\left(0, \ldots,\left(\mathbf{U}^{\mathbf{r}}\right)^{\mathbf{T}}, \ldots, 0\right)^{T} e$

In addition, the embodied carbon intensity of exports (ECIE) from region $r$ can be expressed as $q^{r} /\left(u^{r} \mathrm{e}\right)$.

\subsection{Spatial decomposition of CEE}

We use the provincial MRIO model to construct the decomposition method for analyzing the driving factors of the provincial CEE in China. According to Ang (2004), the LMDI approach is the preferred method compared to other index composition methods. Ang (2005) provides a practical guide for the LMDI method and Ang and Liu (2007) propose a technique for handling the zero values in the LMDI approach. Therefore, we decide to carry out the decomposition analysis by combining the MRIO model and the LMDI approach.

According to Eq. (2), the change in $q$ between time points 0 and $t$ can be decomposed as

$\Delta q=q^{t}-q^{0}=f\left(\Delta \mathbf{C}^{\mathbf{T}}\right)+f(\Delta \mathbf{L})+f(\Delta \mathbf{H})+f(\Delta \mathbf{U})+f(\Delta e)$

where $\Delta$ represents the changes of each variable.

To apply the LMDI approach, we can rewrite Eq. (2) as

$q=\sum_{r} \sum_{j}\left(\sum_{i} \sum_{s} c_{i}{ }^{s} l_{i j}{ }^{s r}\right) h_{j}{ }^{r} u^{r} e$

According to Eq. (5) and following Ang (2005) and Ang and Liu (2007), the components of Eq. (4) can be expressed as

$$
\begin{aligned}
& f\left(\Delta \mathbf{C}^{\mathbf{T}}\right)=\sum_{r} \sum_{j}\left[w_{j}{ }^{r} \sum_{i} \sum_{s} w_{g j}{ }^{s r} \ln \left(c_{i}^{s, t} / c_{i}{ }^{s, 0}\right)\right] \\
& f(\Delta \mathbf{L})=\sum_{r} \sum_{j}\left[w_{j}{ }^{r} \sum_{i} \sum_{s} w_{g j}{ }^{s r} \ln \left(l_{i j}{ }^{s r, t} / l_{i j}{ }^{s r}, 0\right)\right] \\
& f(\Delta \mathbf{H})=\sum_{r} \sum_{j} w_{j}{ }^{r} \ln \left(h_{j}{ }^{r, t} / h_{j}^{r}{ }^{r}, 0\right. \\
& f(\Delta \mathbf{U})=\sum_{r} \sum_{j} w_{j}{ }^{r} \ln \left(u^{r, t} / u^{r, 0}\right) \\
& f(\Delta e)=\sum_{r} \sum_{j} w_{j}{ }^{r} \ln \left(e^{t} / e^{0}\right)
\end{aligned}
$$

where

$$
\begin{aligned}
& w_{j}^{r}=\left[\left(q_{j}^{r, t}-q_{j}^{r, 0}\right) /\left(\ln q_{j}^{r, t}-\ln q_{j}^{r, 0}\right)\right] \\
& w_{g j}{ }^{s r} \\
& \quad=\left[\left(g_{i j}{ }^{s r, t}-g_{i j}{ }_{i j}^{s, 0}\right) /\left(\ln g_{i j}{ }^{s r, t}-\ln g_{i j}{ }^{s r, 0}\right)\right] /\left[\left(g_{j}^{r, t}-g_{j}^{r, 0}\right) /\left(\ln g_{j}^{r, t}-\ln g_{j}^{r, 0}\right)\right]
\end{aligned}
$$

where again $q_{j}{ }^{r}=\left(\sum_{i} \sum_{s} c_{i}{ }^{s} l_{i j}{ }^{s r}\right) h_{j}{ }^{r} u^{r} e, g_{i j}{ }^{s r}=c_{i}{ }^{s} l_{i j}{ }^{s r} \operatorname{andg}_{j}{ }^{r}=\sum_{i} \sum_{s}$ $g_{i j}{ }^{s r}$.

The terms $f\left(\Delta \mathbf{C}^{\mathbf{T}}\right), f(\Delta \mathbf{L}), f(\Delta \mathbf{H}), f(\Delta \mathbf{U})$ and $f(\Delta e)$ are the technique, input structural, composition, distribution and scale effects in CEE, respectively. The technique, composition and scale effects were first used by Grossman and Krueger (1993) to measure the effects of trade on the environment; these terms are widely applied in studies of trade and the environment (Copeland and Taylor, 2004). Copeland and Taylor (2004) defined the technique effect as the impact of the changes in sector DCIs in each region on CEE, leaving everything else unchanged. The composition effect captures the changes in emissions caused by changes in a sector's share of total exports, leaving the other variables unchanged. The scale effect measures the changes in carbon emissions that are generated by the change in the total amount of exports on the condition that everything else remains unchanged. We can augment two more effects using the MRIO model. The input structural effect measures the impact of changes in the sectoral shares on the intra- and interprovincial intermediate input on pollution, leaving everything else unchanged. The distribution effect reflects the impact of changes in the provincial shares on the total national exports on pollution, leaving everything else unchanged. Moreover, $q_{j}^{r}$ and $g_{j}^{r}$ denote the CEE and the embodied carbon intensity (ECI), respectively, of sector $j$ of region $r$.

Similarly, we can decompose the regional CEE, $q^{r}$, as

$$
\begin{aligned}
\Delta q^{r}= & \sum_{j}\left[w_{j}{ }^{r} \sum_{i} \sum_{s} w_{g j}{ }^{s r} \ln \left(c_{i}^{s, t} / c_{i}^{s, 0}\right)\right] \\
& +\sum_{j}\left[w_{j}{ }^{r} \sum_{i} \sum_{s} w_{g j}{ }^{s r} \ln \left(l_{i j}{ }^{s r, t} / l_{i j}{ }^{s r}, 0\right)\right] \\
& +\sum_{j} w_{j}{ }^{r} \ln \left(h_{j}{ }^{r, t} / h_{j}{ }^{r, 0}\right)+\sum_{j} w_{j}{ }^{r} \ln \left(u^{r, t} / u^{r, 0}\right) \\
& +\sum_{j} w_{j}{ }^{r} \ln \left(e^{t} / e^{0}\right)
\end{aligned}
$$

The terms on the right side of Eq. (6) denote the technique, input structure, composition, distribution and scale effects in provincial CEE, respectively.

\subsection{Data preparation}

This study uses MRIO tables, such as China's 30-province and 30sector IO tables for 2007 and 2010. Tibet has been excluded from China's MRIO tables because of a lack of data. The Institute of Geography Sciences and Natural Resources Research, Chinese Academy of Sciences and CNBS compile these two tables. Details of China's MRIO table can be found in Liu et al. $(2012,2014)$. To make the MRIO tables comparable with each other, we deflate the 2010 table to 2007 prices based on the double deflation method (United Nations, 1999). The regional sector price index used in the deflation is obtained from the Statistical Yearbook (various issues) of each province. There is no sector price index for Hunan province from 2007 to 2010 and we use the sector price index for Hubei province as its proxy.

The regional carbon emissions by sector are estimated from the regional energy consumption data by sector based on the method recommended by the Intergovernmental Panel on Climate Change (IPCC, 2006). The regional industrial energy consumption data by sector are also obtained from the Statistical Yearbook (various issues) of each province. The energy consumption data by sector of Hebei province and Shanghai City are respectively obtained from the Hebei Economic Yearbook and Shanghai Statistical Yearbook on Industry and Transport. The regional energy consumption data for agriculture and various 
service sectors are obtained from the Comprehensive Energy Balance Table for each province in the China Energy Statistical Yearbook.

Notably, the regional energy consumption data for the industrial sector in most of the Statistical Yearbooks of the provinces only include data for primary consumed fuels or the total energy consumption. For example, the energy consumption data for the industrial sector for Guangdong province only contain data for total energy consumption, coal and electricity. The energy consumption data for the industrial sector for Hebei, Shandong, Guangxi and Guizhou provinces in 2007 and 2010, for Yunnan province in 2007, and for Hainan province in 2010 only contain total energy consumption. The regional energy consumption data for the industrial sector of some provinces are deficient. The energy consumption data for the industrial sector of Jiangsu, Zhejiang and Sichuan provinces for 2007 and 2010 and those of Hainan province for 2007 are deficient. The Comprehensive Energy Balance Table for each province contains very detailed data of each fuel consumed by the agriculture and aggregated industrial and service sectors, as well as the data of fuels used for energy transformation. However, there are no available data for disaggregated industrial sectors. To estimate the regional sector carbon emissions as reliably as possible, we adopt the following process.

First, we use the regional energy consumption data for the industrial sector to estimate the sector shares in regional total industrial carbon emissions (RTICE). Second, we estimate RTICE using data from the provincial Comprehensive Energy Balance Table. Third, we calculate the regional carbon emissions of the industrial sector based on the shares and RTICE obtained from the previous steps.

In the first step, we use the regional energy consumption data for the industrial sector in China's Economic Census Yearbook 2008 to estimate the industrial sector shares in RTICE for provinces without energy consumption data for the industrial sector. These data for those provinces only contain total energy consumption. Thus, we use data from China's Economic Census Yearbook 2008 to estimate their comprehensive carbon emissions coefficients of energy for the industrial sector, and then the sector shares in RTICE.

\section{Results}

\subsection{Carbon embodied in provincial international exports}

We report only the results obtained using the hybrid approach in this section because the EEBT approach fails to take the full provincial CEE into account, as shown in Section 2.1. For 2007 and 2010, Figs. 1 and 2 show the provincial CEE and ECIEs, respectively. Table 1 shows the provincial share of CEE and share of exports in 2007 and 2010. Evidently, the CEE of China is mainly distributed in the eastern provinces. The CEE of Guangdong province is consistently the largest, which accounts for about one-third and one-fifth of the total CEE in 2007 and 2010, respectively. The CEEs of Jiangsu, Zhejiang, Shandong and Shanghai are important as they are always among the top five and their shares are around 10\% of the total CEE for China. The CEEs of Liaoning, Tianjin, Fujian, Hebei and Beijing provinces are also relatively large. The share of the total CEE of the ten eastern provinces was $86 \%$ and $82 \%$ in 2007 and 2010, respectively, whereas the total CEE share of the other 20 provinces was less than $20 \%$ in the same period.

The distribution of CEE in China follows the distribution of China's exports at the provincial level. The central government of China gradually implemented an opening policy to reduce risks. The opening policy was implemented only in the eastern provinces before 1990 . These provinces have the advantages of technology, skilled labor and capital compared with the other provinces. Therefore, the industrial sectors of these provinces are more developed than those in the other provinces. Moreover, the eastern provinces are located in the coastal area of China and thus have the advantage of sea transportation, which is much cheaper than land transportation (railway and trucks) for heavy bulk commodities traveling long distances. Therefore, when China began to implement the opening policy, the eastern provinces were easily selected as a special economic zone for developing China's international trade. China's opening policy was gradually extended to the other provinces in the 1990s. However, most export-oriented plants still prefer locations in the coastal provinces. Therefore, most of China's exports are from the eastern provinces. The eastern provinces' share in China's total exports was 88\% and 84\% in 2007 and 2010, respectively.

However, much of the CEE of the eastern provinces occurs in other provinces. Most of China's coal, petroleum and natural gas are mined and burned in the interior provinces. However, a large part of the fuels is used to produce products that are consumed by the eastern provinces. Feng et al. (2013) indicated that $50 \%$ of the emissions embodied in products consumed by some of the eastern provinces, including Beijing, Tianjin, Shanghai, Guangdong and Zhejiang, are from other provinces with less efficient technologies. Furthermore, 40\% of the CEE of Shanghai, Jiangsu, Zhejiang, Fujian, Guangdong and Hainan is from other provinces.

It is also evident that the ECIEs of the eastern provinces are generally lower than those of the other provinces. In 2007, the ECIEs of six provinces were lower than the average ECIE, which is the ratio of the
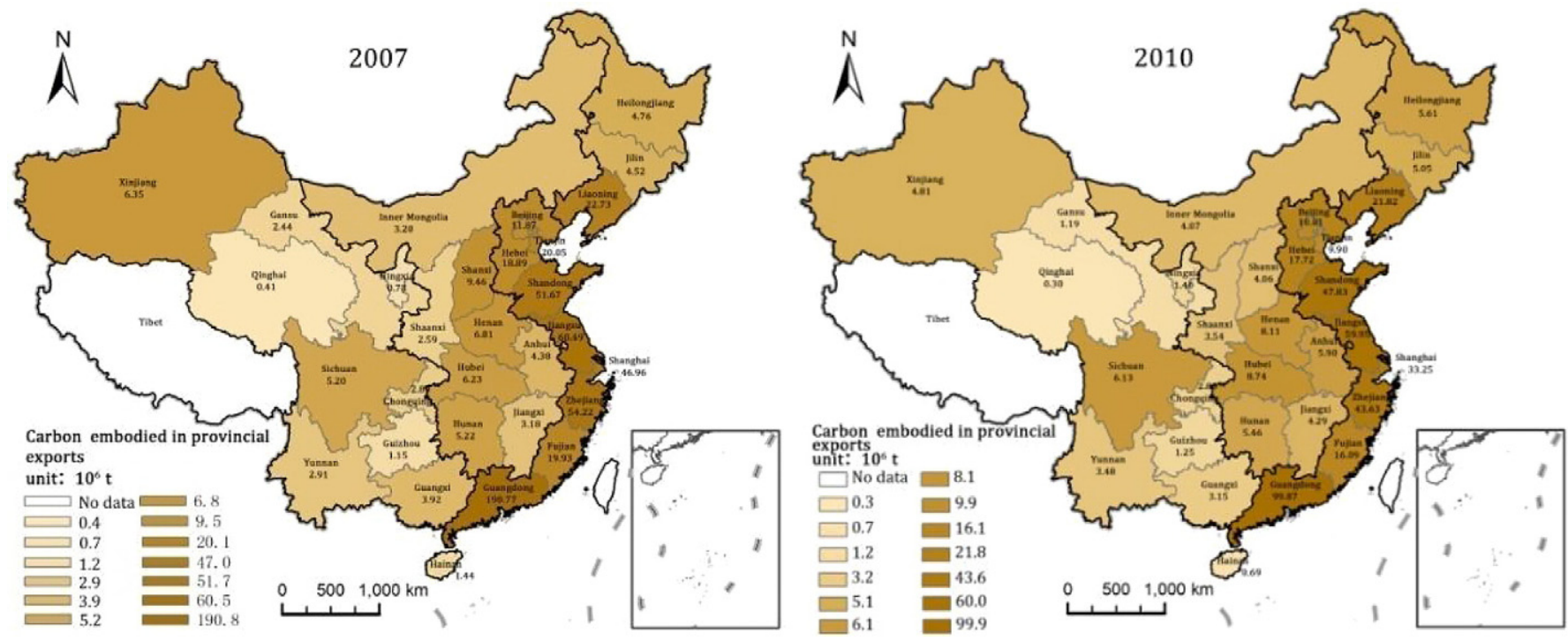

Fig. 1. Provincial CEE in 2007 and 2010. 

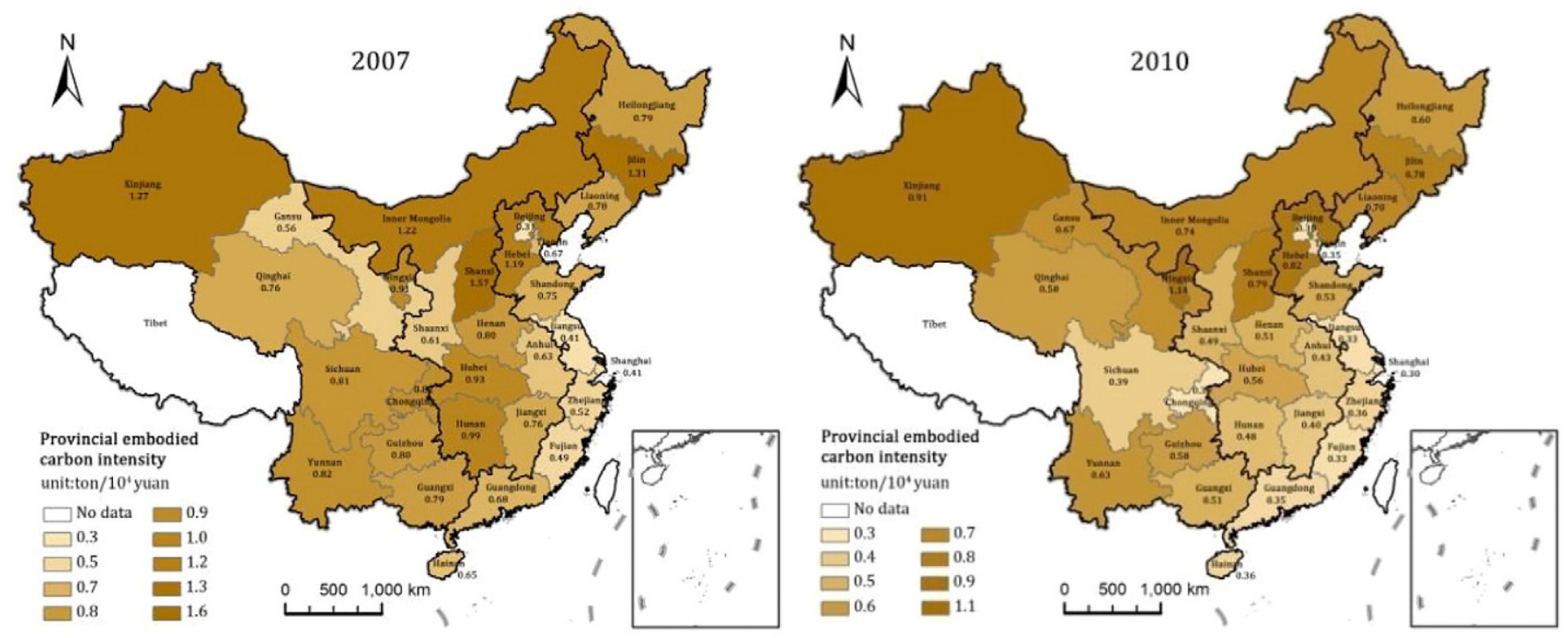

Fig. 2. Provincial ECIEs in 2007 and 2010.

total CEE to total exports. These provinces are Beijing, Shanghai, Jiangsu, Fujian, Zhejiang and Gansu. Five of these provinces are eastern provinces with a total export share of $47 \%$. The ECIEs of all other eastern provinces, except Hebei, are also relatively low. In 2010, the ECIEs of 11 provinces with a total export share of $76 \%$ were lower than the average ECIE. All 11 provinces, except Chongqing and Sichuan, are eastern provinces. In other words, the ECIEs of all eastern provinces, except Shandong and Hebei, are lower than the average ECIE. Further, the ECIEs of Beijing, Shanghai, Jiangsu, and Fujian are consistently the lowest. The ECIEs of the other provinces, except Chongqing and Sichuan, are higher than the average ECIE. The average ECIEs of the eastern provinces were respectively $65 \%$ and $66 \%$ of that of the other provinces in 2007 and 2010.

The provincial ECIEs are determined by the provincial sectoral ECIs and export composition. The sectoral ECIs of eastern provinces are generally lower than those of other provinces because eastern provinces have the advantages of technology compared with other provinces. Moreover, the export composition of most of the eastern provinces is

Table 1

Provincial share of total CEE, exports, energy production and energy consumption.

\begin{tabular}{|c|c|c|c|c|c|c|c|c|c|c|}
\hline \multirow[t]{2}{*}{ Province } & \multicolumn{2}{|c|}{$\begin{array}{l}\text { Share of total CEE } \\
(\%)\end{array}$} & \multicolumn{2}{|c|}{$\begin{array}{l}\text { Share of total } \\
\text { exports(\%) }\end{array}$} & \multicolumn{3}{|c|}{$\begin{array}{l}\text { Share of total energy production in } \\
2007-2010(\%)\end{array}$} & \multicolumn{3}{|c|}{$\begin{array}{l}\text { Share of total energy consumption in } \\
2007-2010(\%)\end{array}$} \\
\hline & 2007 & 2010 & 2007 & 2010 & Coal & Petroleum & Gas & Coal & Petroleum & Gas \\
\hline Beijing & 2.1 & 2.5 & 4.0 & 3.3 & 0.2 & 11.0 & 1.8 & 0.8 & 2.8 & 6.9 \\
\hline Tianjin & 3.5 & 2.3 & 3.1 & 2.5 & 0.0 & 3.4 & 1.1 & 1.2 & 2.7 & 2.0 \\
\hline Hebei & 3.3 & 4.0 & 1.7 & 2.0 & 3.1 & 0.0 & 0.2 & 7.4 & 3.4 & 2.3 \\
\hline Shanxi & 1.6 & 0.9 & 0.6 & 0.5 & 22.6 & 0.0 & 0.0 & 8.3 & 0.0 & 1.6 \\
\hline Inner Mongolia & 0.6 & 0.9 & 0.3 & 0.5 & 17.6 & 6.0 & 1.1 & 6.6 & 0.4 & 4.0 \\
\hline Liaoning & 4.0 & 5.0 & 3.1 & 2.8 & 2.4 & 3.5 & 1.1 & 4.5 & 15.7 & 1.8 \\
\hline Jilin & 0.8 & 1.2 & 0.4 & 0.6 & 1.4 & 21.5 & 3.5 & 2.4 & 2.4 & 1.7 \\
\hline Heilongjiang & 0.8 & 1.3 & 0.6 & 0.9 & 3.5 & 0.1 & 0.6 & 3.2 & 5.0 & 3.4 \\
\hline Shanghai & 8.2 & 7.5 & 11.8 & 10.0 & 0.0 & 1.0 & 0.1 & 1.6 & 5.0 & 3.8 \\
\hline Jiangsu & 10.5 & 13.6 & 15.5 & 16.6 & 0.9 & 0.0 & 0.0 & 6.1 & 6.7 & 6.7 \\
\hline Zhejiang & 9.4 & 9.9 & 10.9 & 10.9 & 0.0 & 0.0 & 0.0 & 3.8 & 6.4 & 2.4 \\
\hline Anhui & 0.8 & 1.3 & 0.7 & 1.2 & 4.1 & 0.0 & 0.0 & 3.4 & 1.2 & 0.9 \\
\hline Fujian & 3.5 & 3.7 & 4.3 & 4.4 & 0.8 & 0.0 & 0.0 & 1.9 & 1.6 & 1.1 \\
\hline Jiangxi & 0.6 & 1.0 & 0.4 & 1.0 & 1.1 & 14.9 & 1.1 & 1.6 & 1.1 & 0.3 \\
\hline Shandong & 9.0 & 10.9 & 7.3 & 8.1 & 5.2 & 2.5 & 2.4 & 10.0 & 12.6 & 4.0 \\
\hline Henan & 1.2 & 1.8 & 0.9 & 1.4 & 7.7 & 0.4 & 0.2 & 7.0 & 2.0 & 4.4 \\
\hline Hubei & 1.1 & 2.0 & 0.7 & 1.4 & 0.4 & 0.0 & 0.1 & 3.3 & 2.4 & 1.7 \\
\hline Hunan & 0.9 & 1.2 & 0.6 & 1.0 & 2.3 & 7.1 & 7.3 & 3.1 & 1.6 & 1.0 \\
\hline Guangdong & 33.2 & 22.7 & 29.3 & 25.7 & 0.0 & 0.0 & 0.4 & 4.0 & 9.2 & 7.5 \\
\hline Guangxi & 0.7 & 0.7 & 0.5 & 0.6 & 0.2 & 0.1 & 0.3 & 1.5 & 0.6 & 0.2 \\
\hline Hainan & 0.3 & 0.2 & 0.2 & 0.2 & 0.0 & 0.0 & 0.6 & 0.2 & 2.1 & 2.9 \\
\hline Chongqing & 0.5 & 0.6 & 0.4 & 0.8 & 1.6 & 0.1 & 24.5 & 1.6 & 0.0 & 5.5 \\
\hline Sichuan & 0.9 & 1.4 & 0.7 & 1.4 & 3.4 & 0.0 & 0.0 & 3.2 & 0.8 & 14.4 \\
\hline Guizhou & 0.2 & 0.3 & 0.2 & 0.2 & 4.3 & 0.0 & 0.0 & 3.0 & 0.0 & 0.5 \\
\hline Yunnan & 0.5 & 0.8 & 0.4 & 0.5 & 2.6 & 0.0 & 0.0 & 2.4 & 0.0 & 0.5 \\
\hline Shaanxi & 0.5 & 0.8 & 0.5 & 0.7 & 0.0 & 13.1 & 18.9 & 2.8 & 4.8 & 5.6 \\
\hline Gansu & 0.4 & 0.3 & 0.5 & 0.2 & 9.0 & 0.4 & 0.1 & 1.4 & 3.7 & 1.4 \\
\hline Qinghai & 0.1 & 0.1 & 0.1 & 0.1 & 1.4 & 1.1 & 5.1 & 0.4 & 0.3 & 2.4 \\
\hline Ningxia & 0.1 & 0.3 & 0.1 & 0.1 & 0.4 & 0.0 & 0.0 & 1.4 & 0.5 & 1.3 \\
\hline Xinjiang & 1.1 & 1.1 & 0.5 & 0.5 & 1.6 & 13.8 & 29.5 & 1.9 & 5.3 & 7.9 \\
\hline Total & 100.0 & 100.0 & 100.0 & 100.0 & 100.0 & 100.0 & 100.0 & 100.0 & 100.0 & 100.0 \\
\hline
\end{tabular}

Note: Provincial shares of total energy production and consumption are calculated based on data from the China Energy Statistical Yearbook. 
helpful for decreasing their ECIEs. The product categories with the lowest ECIs (lower than 0.35 tonnes per 10000 yuan RMB (T/10 $¥$ )), such as Communications, computers and other electronic equipment, Wholesale and retail and Other service activities, accounted for $47 \%$ to $59 \%$ of the exports of Beijing, Tianjin, Shanghai, Jiangsu, Fujian and Guangdong in 2010. The product categories with the highest ECIs (higher than $\left.0.70 \mathrm{~T} / 10^{4} ¥\right)$, such as Non-metallic mineral products, Basic metals, Mining of metals, Mining of coal and Manufacture of fabricated metal products, accounted for only $6 \%$ to $9 \%$ of the exports of these eastern provinces in the same year. The shares of product categories with the lowest ECIs remain relatively low, whereas the shares of product categories with the highest ECIs are relatively higher in the exports of most other provinces compared with most of the eastern provinces. Therefore, the ECIEs of eastern provinces are generally lower than those of other provinces.

\subsection{Decomposition of carbon embodied in provincial international exports}

The total CEE of China decreased by about 135 million tonnes (MT) from 2007 to 2010. The CEE of 17 provinces, including all the eastern provinces, decreased during the same period. Guangdong had the largest CEE decrease, over 90 MT. The provinces that had decreases over 10 MT in CEE were Shanghai, Zhejiang and Tianjin. The CEE decrease for Shanxi, Shandong, Fujian, Xinjiang, Gansu, Hebei and Beijing was between 1 and 6 MT. However, the CEE of other provinces, such as Jiangxi, Henan, Anhui and Hubei increased by over 1 MT during the same period. Changes in the CEE of other provinces were relatively small.

The effects of the five factors on the changes in the provincial CEE from 2007 to 2010 are shown in Table 2. The technique effect reduced almost all provincial CEEs because most of the provincial sector DCIs decreased within the same period. Guangdong has the largest absolute technique effect, which exceeds that of other provincial technique effects, and contributes about $18 \%$ of the total technique effect. The absolute technique effects of Shanghai, Shandong and Zhejiang, which reach more than $41 \%$ of the total technique effect, are also important.
The provinces with a technique effect of over 2 MT are Jiangsu, Beijing, Tianjin, Fujian, Hebei and Shanxi. The technique effects of eastern provinces are larger than those of other provinces. Furthermore, the technique effects of Liaoning, Hainan and Sichuan increased the CEE within the same period.

The input structural effect results from changes in the shares of different product categories used as the intermediate input. A negative (positive) value for the provincial input structural effect implies that the shares of products with lower (higher) DCIs are used in the provincial intermediate inputs for producing exports. The results show that the input structural effects of 25 provinces decrease the CEE. Guangdong also has the largest input structural effect, which contributes about $69 \%$ of the total input structural effect. The input structural effects of Jiangsu and Zhejiang, which reach more than $10 \%$ of the total input structural effect, are also important. The input structural effects of Sichuan, Shandong, Liaoning, Fujian and Hebei are more than 2 MT. The input structural effects increase the CEE of Beijing, Shanghai, Gansu, Ningxia and Xinjiang.

The composition effects arising from the changes in the provincial export composition resulted in a CEE decrease in 26 provinces. The top five composition effects were observed in eastern provinces-Shanghai, Tianjin, Guangdong, Hebei and Zhejiang. The composition effects of Shandong and Fujian, which are also eastern provinces, are relatively large. However, that of Hainan is relatively small. The provinces with the smallest composition effects are western provinces, including Guizhou, Gansu, Ningxia, Sichuan and Qinghai. However, the composition effects increased in four provinces, which include two eastern provinces, namely, Beijing and Jiangsu, and two other provinces, namely, Heilongjiang and Shaanxi.

Changes in the share of provincial exports cause distribution effects. Distribution effects decreased CEE in 11 provinces from 2007 to 2010 because of their reduced export shares. As the most important trade region in China, Guangdong had the largest decrease in export share. This implies that the global financial crisis had the most serious impact

Table 2

Decomposition of provincial CEE (MT).

\begin{tabular}{|c|c|c|c|c|c|c|c|c|}
\hline \multirow[t]{2}{*}{ Province } & \multicolumn{2}{|c|}{ Provincial CEE } & \multicolumn{6}{|c|}{ Driving forces of provincial CEE } \\
\hline & 2007 & 2010 & Technique effect & Input structural effect & Composition effect & Distribution effect & Scale effect & Total $\Delta \mathrm{qr}$ \\
\hline Beijing & 11.87 & 10.81 & -3.87 & 1.06 & 2.21 & -1.89 & 1.43 & -1.06 \\
\hline Tianjin & 20.05 & 9.90 & -3.10 & -1.92 & -4.10 & -2.97 & 1.95 & -10.15 \\
\hline Hebei & 18.89 & 17.72 & -2.04 & -2.07 & -2.43 & 2.87 & 2.49 & -1.18 \\
\hline Shanxi & 9.46 & 4.06 & -2.00 & -1.20 & -1.41 & -1.51 & 0.72 & -5.40 \\
\hline Inner Mongolia & 3.20 & 4.07 & -0.79 & -0.06 & -0.08 & 1.47 & 0.34 & 0.87 \\
\hline Liaoning & 22.73 & 21.82 & 2.73 & -3.33 & -1.58 & -1.78 & 3.05 & -0.91 \\
\hline Jilin & 4.52 & 5.05 & -1.25 & -0.49 & -0.09 & 1.84 & 0.53 & 0.53 \\
\hline Heilongjiang & 4.76 & 5.61 & -0.69 & -0.56 & 0.13 & 1.34 & 0.63 & 0.85 \\
\hline Shanghai & 46.96 & 33.25 & -10.81 & 2.42 & -4.48 & -6.30 & 5.45 & -13.71 \\
\hline Jiangsu & 60.49 & 59.95 & -5.37 & -7.80 & 0.53 & 3.85 & 8.25 & -0.54 \\
\hline Zhejiang & 54.22 & 43.63 & -8.09 & -6.71 & -2.40 & -0.10 & 6.71 & -10.60 \\
\hline Anhui & 4.38 & 5.90 & -1.29 & -0.03 & -0.33 & 2.51 & 0.67 & 1.52 \\
\hline Fujian & 19.93 & 16.09 & -2.54 & -3.13 & -1.15 & 0.54 & 2.45 & -3.84 \\
\hline Jiangxi & 3.18 & 4.29 & -1.76 & -0.00 & -0.34 & 2.71 & 0.48 & 1.10 \\
\hline Shandong & 51.67 & 47.83 & -10.58 & -3.49 & -1.51 & 5.25 & 6.49 & -3.84 \\
\hline Henan & 6.81 & 8.11 & -0.58 & -1.07 & -1.08 & 3.10 & 0.92 & 1.29 \\
\hline Hubei & 6.23 & 8.74 & -1.35 & -0.65 & -0.83 & 4.46 & 0.88 & 2.51 \\
\hline Hunan & 5.22 & 5.46 & -1.70 & -0.32 & -1.15 & 2.81 & 0.62 & 0.24 \\
\hline Guangdong & 190.77 & 99.87 & -12.90 & -76.18 & -2.96 & -17.73 & 18.87 & -90.90 \\
\hline Guangxi & 3.92 & 3.15 & -0.84 & -0.49 & -0.16 & 0.25 & 0.47 & -0.77 \\
\hline Hainan & 1.44 & 0.69 & 0.04 & -0.57 & -0.08 & -0.27 & 0.13 & -0.75 \\
\hline Chongqing & 2.89 & 2.80 & -0.16 & -1.56 & -0.90 & 2.16 & 0.37 & -0.09 \\
\hline Sichuan & 5.20 & 6.13 & 0.03 & -3.54 & -0.03 & 3.76 & 0.70 & 0.93 \\
\hline Guizhou & 1.15 & 1.25 & -0.05 & -0.06 & -0.07 & 0.18 & 0.10 & 0.10 \\
\hline Yunnan & 2.91 & 3.48 & -0.08 & -0.41 & -0.15 & 0.83 & 0.38 & 0.57 \\
\hline Shaanxi & 2.59 & 3.54 & -0.44 & -0.01 & 0.14 & 0.92 & 0.34 & 0.95 \\
\hline Gansu & 2.44 & 1.19 & -0.19 & 0.38 & -0.06 & -1.59 & 0.22 & -1.25 \\
\hline Qinghai & 0.41 & 0.30 & -0.05 & -0.03 & -0.02 & -0.06 & 0.04 & -0.12 \\
\hline Ningxia & 0.73 & 1.40 & -0.11 & 0.42 & -0.04 & 0.27 & 0.13 & 0.67 \\
\hline Xinjiang & 6.35 & 4.81 & -1.51 & 0.65 & -0.99 & -0.41 & 0.72 & -1.54 \\
\hline Total & 575.37 & 440.89 & -71.35 & -110.77 & -25.41 & 6.49 & 66.55 & -134.49 \\
\hline
\end{tabular}


on the exports of Guangdong. The province with the second largest decrease in export share was Shanghai. The decrease in the export shares of Beijing and Tianjin were also relatively large. Hainan and Zhejiang, which are both eastern provinces, also experienced a decrease in export share. However, not all provinces with decreases in export shares are eastern provinces. Other provinces that experienced the same decrease are Gansu, Liaoning, Shanxi, Xinjiang and Qinghai. The export shares of 19 provinces, most of which are non-eastern provinces, increased in 2007 to 2010. However, the export shares of four eastern provinces, Jiangsu, Shandong, Fujian and Hebei, rose during the same period. The increase in the export shares of Jiangsu and Shandong was the largest. The distribution effects are in accordance with the changes in provincial export shares in direction and extent. For example, the changes in the export shares of Guangdong were the largest, as is the distribution effect.

The total exports of China increased by 15\% between 2007 and 2010, with an annual rate of $4.8 \%$. The resulting scale effects of this change increased the CEE of all provinces. The scale effects of Ningxia, Anhui and Jiangxi exceeded $15 \%$. Twenty provinces, including Hubei, had a scale effect of between $10 \%$ and $15 \%$. The remaining seven provinces, such as Guangdong, had a scale effect of less than $10 \%$. However, the growth rate of exports between 2007 and 2010 was lower than pre-2007. According to Zhang (2012), the annual growth rate of exports from 1987 to 2007 was $16 \%$. This rate was as high as $29 \%$ for the beginning of the period at the end of 2001 when China joined the WTO. The most important factor that decreased the growth rate of China's exports from 2007 to 2010 was the global financial crisis, which seriously restrained the international demand for China's commodities. Thus, the total and provincial scale effects are not very important in this period.

The technique effects of seven provinces, namely, Beijing, Shanxi, Shanghai, Zhejiang, Shandong, Guangxi and Xinjiang, have the most important contributions to the changes in CEE. The input structural effects play the most important role in the changes in CEE of Liaoning, Fujian, Guangdong, Hainan and Ningxia. The distribution effects are the most important part of the changes in the CEE of 16 provinces, namely, Hebei, Inner Mongolia, Jilin, Heilongjiang, Anhui, Jiangxi, Henan, Hubei, Hunan, Chongqing, Sichuan, Guizhou, Yunnan, Shanaxi, Gansu and Qinghai. Furthermore, the scale and composition effects make the most contributions to the changes in the CEE of Jiangsu and Tianjin, respectively.

\subsection{Decomposition of total carbon embodied in China's exports}

The last line of Table 2 shows the decomposition of the total CEE of China from 2007 to 2010. Considering that the DCIs of all sectors decreased except those for Mining of metals, Chemicals and chemical products and Other service activities, the average DCI also decreased by around a $1 / 5$ in the entire period (see the last line of Table 3 ). The changes in sector DCIs also contributed to the changes in total CEE. The total technique effect resulted in a $12 \%$ reduction of total CEE. Moreover, the technique effect reflected the total effect of the changes in sectoral energy intensities and sectoral energy mix. According to data from the China Statistical Yearbook 2014, energy intensity decreased by $12 \%$ from 2007 to 2010, whereas the share of renewable energy in China's total energy consumption increased by at least $1 \%$ during the same period. The changes in energy intensities contribute most of the technique effect, whereas small changes in the energy mix do not have a significant effect on CEE.

The changes in the structure of intermediate inputs are the most important for the changes in the CEE of the six provinces. These changes led to a large reduction in the total CEE. The average DCI of the sectors with decreasing shares in the total intermediate inputs was always significantly higher than that of the sectors with increasing shares during the whole period. The average $\mathrm{DCl}$ of the sectors with decreasing shares was $0.43 \mathrm{~T} / 10^{4} ¥$ in 2007 and $0.33 \mathrm{~T} / 10^{4} ¥$ in 2010 , whereas that of the latter group was $0.23 \mathrm{~T} / 10^{4} ¥$ in 2007 and $0.16 \mathrm{~T} / 10^{4} ¥$ in 2010 . Therefore, the input structural effect is beneficial in reducing the total CEE.

The composition effects do not only decrease most of the provincial CEEs, but also reduce the total CEE effectively. Table 3 shows the sector CEEs, ECIs and export shares for China. We can observe in the study period the rising export shares in sectors with the lowest ECIs, such as Communications, computers and other electronic equipment, Instruments, watches and clocks, Wholesale and retail, Leasing and commercial services and Other service activities, as well as the decreasing export shares in sectors with higher ECIs, such as Basic metals. Therefore, changes in export composition can reduce the total CEE.

The distribution effect causes a small increase in the total CEE. As mentioned above, the export shares of 11 provinces, including provinces with the lowest ECIs, such as Guangdong, Shanghai, Beijing and Tianjin, decreased from 2007 to 2010. Further analysis shows that the average ECI of 11 provinces whose export shares decreased was $0.60 \mathrm{~T} / 10^{4} ¥$ and $0.37 \mathrm{~T} / 10^{4} ¥$ in 2007 and 2010 , respectively. These figures are a bit lower than the average ECI of $0.61 \mathrm{~T} / 10^{4} ¥$ and $0.44 \mathrm{~T} / 10^{4}$ $¥$ between 2007 and 2010, respectively, of the other 19 provinces. Thus, the distribution effect is helpful in reducing the total CEE, even if it is small.

The increase in total exports was the most important factor in the change in China's CEE in 1987-2007 (Zhang, 2012). However, the scale effect in 2007-2010 only increased the total CEE of China by $12 \%$, which is far lower than its historical level, because the global financial crisis heavily decreased foreign demand for China's products. The relative importance of the scale effect also declined, becoming only about $2 / 3$ of the input structural effect. It is also significantly smaller than the technique effect.

\section{Discussion}

The provincial CEE of China in 2007 and 2010 is calculated using the MRIO tables for 30 provinces. The global financial crisis that occurred in 2008 significantly affected China's exports, and its effect on the exports of different regions clearly differed. However, the crisis did not change the basic regional distribution characteristics of China's exports (Zhang and Wei, 2011). Thus, the global financial crisis did not significantly change the regional distribution of the national CEE of China. The eastern (coastal) provinces contributed most of the CEE of China both before and after the global financial crisis (Table 1).

Several previous studies estimate the regional CEEs of China before the global financial crisis. The results of Guo et al. (2012), Feng et al. (2013) and Weitzela and Ma (2014) also indicate that the CEEs of the eastern (coastal) area are much larger than those of other areas. Like Su and Ang (2010, 2014) and Weitzela and Ma (2014), our results show that the ECI of the eastern area is much lower than those of other areas. Like Guo et al. (2012), we also calculate the sector CEEs of China and find that most of the CEEs are from secondary industries. However, previous studies focus on the regional CEEs of China in a typical year but few of them compare the regional CEEs between two years and analyze the driving forces of the changes in regional CEEs.

The findings are quite sensitive to the differences in interprovincial trade estimation. Weitzela and Ma (2014) calculated the total CEE of China in 2007 and used the gravity model to estimate the interprovincial trade flows of China. Conversely, the interprovincial trade flows in our MRIO model are estimated using an extended gravity model, which introduces spatially lagged dependent variables to deal with the mixed-origin destination-based spatial dependence of trade flows (Liu et al., 2012). The total amount of domestic $\mathrm{CO}_{2}$ embodied in China's exports in 2007 was calculated by Weitzela and Ma (2014) as 1730 MT (472 MT of carbon) using the hybrid approach, which considers interprovincial trade flows. Their result is less than our result (575 MT of carbon), which is estimated using the same approach. However, our estimation of China's total CEE (290 MT of carbon) used the EEBT approach (Appendix A), which does not consider interprovincial 
Table 3

Sector CEE, DCIs, ECIs and shares in total intermediate inputs and total exports.

\begin{tabular}{|c|c|c|c|c|c|c|c|c|c|c|}
\hline \multirow[t]{2}{*}{ Sector } & \multicolumn{2}{|c|}{ CEE (MT) } & \multicolumn{2}{|c|}{ DCI (T/104¥) } & \multicolumn{2}{|c|}{$\begin{array}{l}\text { Share of total } \\
\text { intermediate } \\
\text { inputs (\%) }\end{array}$} & \multicolumn{2}{|c|}{ ECI (T/104¥) } & \multicolumn{2}{|c|}{$\begin{array}{l}\text { Share of total } \\
\text { exports }(\%)\end{array}$} \\
\hline & 2007 & 2010 & 2007 & 2010 & 2007 & 2010 & 2007 & 2010 & 2007 & 2010 \\
\hline Agriculture & 2.97 & 1.89 & 0.06 & 0.05 & 7.05 & 5.48 & 0.45 & 0.27 & 0.70 & 0.64 \\
\hline Mining of coal & 2.19 & 0.97 & 0.30 & 0.27 & 2.13 & 2.16 & 0.95 & 0.83 & 0.24 & 0.11 \\
\hline Mining of oil and gas & 0.86 & 0.77 & 0.16 & 0.14 & 1.70 & 1.48 & 0.60 & 0.55 & 0.15 & 0.13 \\
\hline Mining of metals & 0.69 & 0.68 & 0.05 & 0.07 & 1.12 & 1.48 & 0.82 & 0.97 & 0.09 & 0.06 \\
\hline Mining of non-metals & 1.23 & 0.91 & 0.09 & 0.07 & 0.66 & 0.73 & 0.67 & 0.63 & 0.19 & 0.13 \\
\hline Food and beverages & 9.52 & 6.24 & 0.06 & 0.04 & 3.95 & 4.61 & 0.50 & 0.31 & 2.01 & 1.82 \\
\hline Textiles & 37.48 & 33.23 & 0.05 & 0.04 & 2.88 & 3.58 & 0.46 & 0.38 & 8.54 & 7.87 \\
\hline Clothing, dressing and dyeing of fur & 28.88 & 16.19 & 0.02 & 0.01 & 1.26 & 1.58 & 0.51 & 0.29 & 5.90 & 5.16 \\
\hline Wood and wood products & 16.57 & 9.81 & 0.03 & 0.02 & 1.26 & 1.34 & 0.68 & 0.38 & 2.55 & 2.35 \\
\hline Paper and products for culture, education and sports & 16.56 & 10.06 & 0.09 & 0.08 & 2.53 & 2.60 & 0.72 & 0.46 & 2.39 & 1.98 \\
\hline Refined petroleum products, coking products and coal gas and coal gas products & 6.76 & 5.13 & 0.34 & 0.25 & 4.06 & 3.03 & 0.85 & 0.79 & 0.83 & 0.59 \\
\hline Chemicals and chemical products & 54.95 & 56.19 & 0.12 & 0.15 & 10.85 & 10.63 & 0.76 & 0.62 & 7.58 & 8.17 \\
\hline Non-metallic mineral products & 22.19 & 20.51 & 1.41 & 1.04 & 4.19 & 4.70 & 1.50 & 1.18 & 1.55 & 1.58 \\
\hline Basic metals & 71.68 & 36.96 & 0.52 & 0.38 & 11.31 & 10.49 & 1.39 & 1.09 & 5.40 & 3.08 \\
\hline Fabricated metal products & 28.94 & 24.16 & 0.02 & 0.02 & 2.95 & 2.72 & 0.82 & 0.75 & 3.71 & 2.94 \\
\hline Machinery & 28.37 & 33.94 & 0.04 & 0.02 & 3.31 & 4.28 & 0.49 & 0.49 & 6.05 & 6.29 \\
\hline Transport equipment & 16.11 & 19.76 & 0.02 & 0.01 & 3.45 & 4.08 & 0.49 & 0.39 & 3.44 & 4.59 \\
\hline Electrical machinery and apparatus & 43.40 & 40.82 & 0.01 & 0.01 & 3.08 & 3.25 & 0.64 & 0.44 & 7.14 & 8.39 \\
\hline Communications, computers and other electronic equipment & 102.12 & 44.31 & 0.01 & 0.00 & 3.00 & 3.86 & 0.48 & 0.16 & 22.38 & 24.66 \\
\hline Instruments, watches and clocks & 15.58 & 9.93 & 0.01 & 0.00 & 0.36 & 0.44 & 0.52 & 0.28 & 3.13 & 3.23 \\
\hline Other industrial activities & 6.29 & 7.49 & 0.02 & 0.02 & 0.99 & 1.05 & 0.47 & 0.44 & 1.41 & 1.56 \\
\hline Production and distribution of electricity and heat & 1.08 & 1.85 & 2.35 & 1.95 & 6.32 & 5.17 & 1.67 & 2.47 & 0.07 & 0.07 \\
\hline Steam and water supply & 0.00 & 0.00 & 0.50 & 0.37 & 0.32 & 0.32 & 1.34 & 0.79 & 0.00 & 0.00 \\
\hline Construction & 2.91 & 5.78 & 0.02 & 0.02 & 0.58 & 0.62 & 0.71 & 0.67 & 0.43 & 0.79 \\
\hline Transportation and warehousing & 27.43 & 21.58 & 0.33 & 0.25 & 5.10 & 5.10 & 0.69 & 0.65 & 4.18 & 3.01 \\
\hline Wholesale and retail & 12.77 & 13.35 & 0.05 & 0.04 & 3.90 & 3.89 & 0.31 & 0.22 & 4.30 & 5.43 \\
\hline Hotels and restaurants & 2.83 & 2.00 & 0.05 & 0.05 & 1.59 & 1.58 & 0.35 & 0.36 & 0.85 & 0.50 \\
\hline Leasing and commercial services & 11.14 & 12.35 & 0.01 & 0.01 & 1.92 & 1.98 & 0.34 & 0.33 & 3.39 & 3.43 \\
\hline Research and development & 0.08 & 0.18 & 0.02 & 0.01 & 0.19 & 0.18 & 0.31 & 0.36 & 0.03 & 0.05 \\
\hline Other service activities & 3.78 & 3.87 & 0.02 & 0.02 & 8.00 & 7.59 & 0.29 & 0.25 & 1.37 & 1.40 \\
\hline Total & 575.37 & 440.89 & $0.23^{\mathrm{a}}$ & $0.18^{\mathrm{a}}$ & 100 & 100 & $0.60^{\mathrm{b}}$ & $0.40^{\mathrm{b}}$ & 100 & 100 \\
\hline
\end{tabular}

a Average DCI, which is the ratio of total carbon emissions to total inputs.

b Average ECI, which is the ratio of total CEE to total exports.

trade flows, and it is significantly lower than their result (423 MT of carbon) under the same approach. The comparison implies that the differences in interprovincial trade estimates lead to significantly different findings.

The methods used in this study for estimating the disaggregated sectoral emissions at the regional level may cause uncertainties in the results. CNBS annually publishes national and provincial energy statistics. However, the emissions estimated, based on the national account, are significantly smaller than those calculated based on the regional account (Guan et al., 2012). Moreover, the energy statistics for aggregated sectors are complete in the national and provincial accounts, whereas the disaggregated sectoral energy data are complete for the national scale but incomplete for most of the provinces.

Su and Ang (2010) provided an optimization method (see their Appendix B) to estimate the sectoral emissions for China's regions. The current study also used the regional sectoral energy dataset to estimate the regional emissions of sectors other than mining and manufacturing. However, Su and Ang's (2010) procedure for estimating the regional carbon emissions of the mining and manufacturing sectors is different from our method. They allocated the national sectoral carbon emissions to regional carbon emissions using the RAS method. In our study, we estimated the regional sectoral carbon emissions mainly using the regional sectoral energy dataset, which is collected from various sources. Su and Ang (2010) used the sum of the sectoral energy data in all the regional accounts to make adjustments to the sectoral energy data in the national account. Conversely, we used the sectoral carbon emissions estimated based on the national account to adjust the regional sectoral carbon emissions obtained using the regional account.

Weitzela and Ma (2014) also used the emissions estimated based on the national energy statistics to adjust regional emissions. However, they proportionally attributed energy consumption to the different sectors in terms of the energy value input share of each corresponding sector in the IO table. Therefore, their method for estimating the regional sectoral emissions is slightly similar to that of Su and Ang (2010) but different from ours. The different methods for estimating regional sectoral emissions must have caused the differences between our results and those of Weitzela and Ma (2014).

Zhang and Lahr (2014) decomposed China's energy consumption change using the multiplicative SDA and seven-region (each region is composed of several provinces) and seven-sector MRIO tables for China. We use the additive SDA and the 30-province and 30-sector MRIO tables for disaggregated 30 provinces. Zhang and Lahr (2014) also found that exports played a major role in the increase in energy consumption in most regions, as we report in this paper. However, Zhang and Lahr (2014) concluded that China's exports became more energy intensive in 2002 and 2007, whereas we find China's exports became less carbon intensive in 2007 and 2010. Zhang and Lahr (2014) reported that the energy embodied in the exports from central China and western China is the largest, whereas we find the CEE of these two regions is far less than that of north China, east China and south China. Yu (2012) analyzed China's provincial energy intensity using spatial statistics and found foreign trade had a very weak influence on provincial energy intensity. However, our results obtained using the MRIO model indicate that foreign trade has a significant effect on China's carbon emissions. The main reason why our finding is different from Yu (2012) is that we take the indirect effect of foreign trade into account while $\mathrm{Yu}$ (2012) did not consider the indirect effect.

Furthermore, some other uncertainties in the results should also be addressed. First, we had to use approximate data as proxies because of the lack of energy consumption and price index data in some provinces. 
Second, we do not distinguish between processing exports and normal exports in this paper unlike some previous studies. This export assumption may have a significant impact on some of the regional CEEs and the national CEE (Dietzenbacher et al., 2012; Su et al., 2013; Weitzela and $\mathrm{Ma}, 2014)$. Third, sector aggregation will also cause uncertainty in the results (Su et al., 2010).

\section{Conclusions and policy implications}

We empirically study the driving forces of carbon emissions embodied in China's provincial exports and total national exports in 2007 to 2010 using the latest provincial MRIO tables for China and the LMDI method. These driving forces are divided into the changes in the total amount of exports, the provincial distribution of exports, the composition of exports, the intermediate input structure and the sectoral emissions intensities. The conclusions and relevant policy implications of the empirical findings are presented below.

Considering the global financial crisis in the period studied, the growth rate of China's exports decreased and the scale effect caused by the increase of the total export was smaller than before. However, total exports continued to grow in the period. The central government of China decided to develop Chinese international trade further by implementing a free-trade zone strategy, such as the Shanghai free-trade zone. We expect that China's exports will grow continuously in the future. Therefore, China should continue to pay attention to the impact of exports on carbon emissions.

The technique effect is caused by the decrease in sectoral emission intensities of most of the provinces during this period. It exceeds the scale effect in the embodied carbon emissions of the total exports. The decreased sectoral emission intensities may be partly caused by the energy conservation policies implemented in the 11th five-year period (2006-2010) in China. The state council of China established a special leader group responsible for decreasing China's energy intensity. The official governors at each governmental level and the chief officers of various companies are responsible for the goals of reducing energy intensity. Similarly, China also adopted a series of comprehensive measures, such as the Energy Conservation Law, controlling the growth of energy-intensive sectors, eliminating the backward capacity in energy-intensive sectors, subsidizing energy-efficient products and implementing key energy conservation projects, to improve energy efficiency. The established institutions, schemes and policies should be kept and implemented in the future.

The total input structural effect is even larger than the technique effect. The changes in the intermediate input structure are the most important factor for the decrease in total exports related to carbon emissions. They also decreased the export-related carbon emissions of most of the provinces. The results of the national and provincial input structural effects imply that less carbon-intensive products are obtained through the total intermediate inputs of the whole country and most of its provinces. The government should encourage producers to use cleaner materials as a substitute for carbon-intensive products by adopting economic instruments, such as a carbon tax and administrative instruments (e.g., extended producer responsibility) in the future.

The most important policy for energy conservation for trade in China is limiting the export of energy-, pollution- and capital-intensive commodities in the 11th five-year period. The declining share of carbonintensive commodities in total exports implies that the above policy has taken effect and the composition effect has brought an important reduction in the carbon embodied in total exports and most of the provincial exports. Similarly, China should continue to implement this policy. Moreover, China should exert more effort to develop a service trade that will optimize the export composition further and reduce export-related carbon emissions.

More than $80 \%$ of the carbon emissions embodied in China's exports are contributed by the eastern provinces, but the contribution of the other provinces has increased significantly. Moreover, exports from the eastern provinces also cause carbon emissions in other provinces because a deep economic linkage exists between provinces. The carbon embodied in the interprovincial trade contributes about $40 \%$ of the total CEE of China. Therefore, China does not only need to optimize the export composition of eastern provinces but should also improve the energy efficiencies of the other provinces. To encourage energy conservation activities in the other provinces, China should implement bias policies for them, such as subsiding energy-saving behaviors, because their development lags behind the eastern provinces. It is also important for the eastern provinces to help the inland provinces to improve their energy efficiency by means of technology transfer, ecological compensation, financial support, training talents and economic cooperation. Further, the inland provinces should implement local polices, such as taxes, subsidies and credits, to encourage technological innovation by local enterprises. At the same time, the governments of the inland provinces should implement better environmental standards for investment to limit or deter the transfer of pollution-intensive industries from eastern provinces.

\section{Acknowledgment}

The authors are grateful for financial support through the National Social Science Foundation of China (grant no. 13CJY009), the National Natural Science Foundation of China (grant no. 41201129), the Innovation Program of the Chinese Academy of Social Sciences and the Key Deploy Program of the Chinese Academy of Sciences (grant no. KZZDEW-06-02). We also gratefully acknowledge many helpful comments and suggestions of the three anonymous referees.

\section{Appendix A. Comparison of the provincial MRIO and SRIO models in estimating CEE.}

The approach based on the provincial SRIO model is in fact the EEBT approach at the provincial level and it is used by some researchers (such as Guo et al., 2012) to estimate the provincial CEE in China. To compare the hybrid approach and the EEBT approach, we present the EEBT approach as follows.

Using the provincial SRIO model, we can write the total CEE as

$q^{\prime}=\sum_{r} q^{r^{\prime}}=\sum_{r}\left(\mathbf{C}^{\mathbf{r}}\right)^{\mathbf{T}} \mathbf{L}^{\mathbf{r}} \mathbf{E}^{\mathbf{r}}$

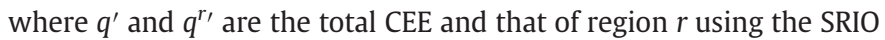
model, respectively. $\mathbf{C}^{\mathbf{r}}$ is the $K \times 1 \mathrm{DCI}$ vector of region $r$, the element of which is $c_{i}^{r} \cdot \mathbf{L}^{\mathbf{r}}=\left(\mathbf{I}-\mathbf{A}^{\mathbf{r}}\right)^{-1}$ is the $n \times n$ regional Leontief inverse of region $r$, the element of which is $l_{i j}^{r r}$.

Compared to the hybrid approach (see Eq. (3)), if the EEBT approach is used, a significant part of a country's emissions embodied in its international trade will be allocated to its interregional trade, as Su and Ang (2014) point out. Similarly, if the EEBT approach is used to calculate the CEE of a province in China, a significant part of its CEE will also be allocated to the interregional trade between it and other provinces. The part of its CEE that is not taken into account is the local emissions in other provinces in China but caused by its international exports through the interprovincial trade between it and other provinces.

Fig. A1 shows the ratios of CEE calculated using the EEBT approach to those calculated under the hybrid approach at the provincial and national levels. It is evident that all the ratios are less than 1 and the average of the ratios is 0.59 and 0.63 for 2007 and 2010, respectively. In other words, if the EEBT approach is used, the provincial and total CEEs will be significantly smaller than those calculated using the hybrid approach, and about $40 \%$ of the total carbon emissions embodied in Chinese international exports will be allocated to the interprovincial trade in China. These empirical findings are in accordance with our theoretical analysis. 


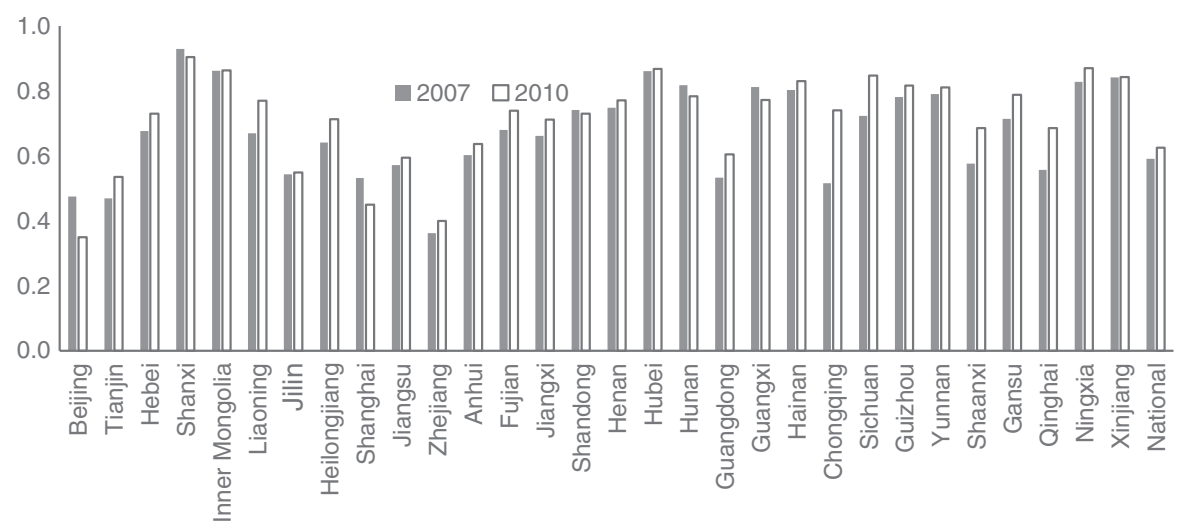

Fig. A1. Ratios of CEE calculated using the EEBT approach to those calculated under the hybrid approach at the provincial and national levels.

\section{Appendix B. Supplementary data}

Supplementary data to this article can be found online at http://dx. doi.org/10.1016/j.eneco.2015.08.002.

\section{References}

Ahmed, N., Wyckoff, A., 2003. Carbon dioxide emissions embodied in international trade, OECD DSTI/DOC(2003)15.

Andrew, R., Peters, G.P., Lennox, J., 2009. Approximation and regional aggregation in multi-regional input-output analysis for national carbon footprint accounting. Econ. Syst. Res. 21, 311-335.

Ang, B.W., 2004. Decomposition analysis for policymaking in energy: which is the preferred method? Energy Policy 32, 1131-1139.

Ang, B.W., 2005. The LMDI approach to decomposition analysis: a practical guide. Energy Policy 33, 867-871.

Ang, B.W., Liu, N., 2007. Handling zero values in the logarithmic mean Divisia index decomposition approach. Energy Policy 35, 238-246.

Atkinson, G., Hamilton, K., Ruta, G., et al., 2011. Trade in "virtual carbon": empirical results and implications for policy. Glob. Environ. Chang. 21 (2), 563-574.

Center, China State Information, 2005. Multi-regional Input-Output Model China's Interregional Input-Output Table. China Statistics Press, Beijing (in Chinese).

Copeland, B.R., Taylor, M.S., 2004. Trade, growth, and the environment. J. Econ. Lit. 42 (1), 7-71.

Dietzenbacher, E., Los, B., 1998. Structural decomposition techniques: sense and sensitivity. Econ. Syst. Res. 10, 307-323.

Dietzenbacher, E., Pei, J., Yang, C., 2012. Trade, production fragmentation, and China's carbon dioxide emissions. J. Environ. Econ. Manag. 64 (1), 88-101.

Feng, K., Siu, Y.L., Guan, D., Hubacek, K., 2012. Analyzing drivers of regional carbon dioxide emissions for China. J. Ind. Ecol. 16, 600-611.

Feng, K., Davis, S.J., Sun, L., Li, X., Guan, D., Liu, W., Liu, Z., Hubacek, K., 2013. Outsourcing $\mathrm{CO}_{2}$ within China. Proc. Natl. Acad. Sci. U. S. A. 110, 11654-11659.

Gao, H., Xiong, Y., Hu, S., 2009, Mar.-Apr.r. The global crisis and its impact on China's economy. China, Economistpp. 80-89.

Grossman, G.M., Krueger, A.B., 1993. Environmental Impacts of a North American Free Trade Agreement. In: Garber, Peter M. (Ed.), The U.S.-Mexico Free Trade Agreement. MIT Press, Cambridge, MA, pp. 13-56.

Guan, D., Hubacek, K., Weber, C.L., Peters, G.P., Reiner, D.M., 2008. The drivers of Chinese $\mathrm{CO}_{2}$ emissions from 1980 to 2030. Glob. Environ. Chang. 18, 626-634.

Guan, D., Liu, Z., Geng, Y., Lindner, S., Hubacek, K., 2012. The gigatonne gap in China's carbon dioxide inventories. Nat. Clim. Chang. 2, 672-675.

Guo, J., Zhang, Z., Meng, L., 2012. China's provincial $\mathrm{CO}_{2}$ emissions embodied in international and interprovincial trade. Energy Policy 42, 486-497.

Hoekstra, R., Van den Bergh, J.C.J.M., 2003. Comparing structural and index decomposition analysis. Energy Econ. 25, 39-64.

$\mathrm{Hu}, \mathrm{Q}$., Li, H., 2010. Empirical analysis on influence of financial crisis to trade of China. J. Int. Trade 36 (3), 3-11 (in Chinese).

IPCC, 2006. IPCC Guidelines for National Greenhouse Gas Inventories 2006. Institute for Global Environmental Strategies, Japan.

Li, Y., Hewitt, C.N., 2008. The effect of trade between China and the UK on national and global carbon dioxide emissions. Energy Policy 36 (6), 1907-1914.

Lin, B., Sun, C., 2010. Evaluating carbon dioxide emissions in international trade of China. Energy Policy 38, 613-621.

Liu, L., 2009. Impact of the global financial crisis on China: empirical evidence and policy implications. China World Econ. 17 (6), 1-23.

Liu, X., Ishikawa, M., Wang, C., Dong, Y., Liu, W., 2010. Analyses of $\mathrm{CO}_{2}$ emissions embodied in Japan-China trade. Energy Policy 38 (1), 613-621.

Liu, W., Chen, J., Tang, Z., Liu, H., Han, D., Li, F., 2012. China's Interregional Input-output Table for 30 Provinces, Cities and Regions in 2007. China Statistics Press, Beijing (in Chinese).
Liu, W., Tang, Z., Chen, J., Yang, B., 2014. China's Interregional Input-output Table for 30 Provinces, Cities and Regions in 2010. China Statistics Press, Beijing (in Chinese).

Meng, L., Guo, J., Chai, J., Zhang, Z., 2011. China's regional $\mathrm{CO}_{2}$ emissions: characteristics, inter-regional transfer and emission reduction policies. Energy Policy 39, 6136-6144.

Meng, B., Xue, J., Feng, K., Guan, D., Fu, X., 2013. China's inter-regional spillover of carbon emissions and domestic supply chains. Energy Policy 61, 1305-1321.

Miller, R.E., Blair, P.D., 2009. Input-output analysis. Foundations and Extensions. Cambridge University Press.

Minx, J., Baiocchi, G., Peters, G., Weber, C., Guan, D., Hubacek, K., 2011. A carbonizing dragon: China's fast growing $\mathrm{CO}_{2}$ emissions revisited. Environ. Sci. Technol. 45 9144-9153.

Pan, J., Phillips, J., Chen, Y., 2008. China's balance of emissions embodied in trade: approaches to measurement and allocating international responsibility. Oxf. Rev. Econ. Policy 24 (2), 354-376.

Peters, G.P., 2008. From production-based to consumption-based national emissions inventories. Ecol. Econ. 65 (1), 13-23.

Peters, G., Weber, C.L., Guan, D., Hubacek, K., 2007. China's growing $\mathrm{CO}_{2}$ emissions-a race between lifestyle changes and efficiency gains. Environ. Sci. Technol. 41, 5939-5944.

Qi, T., Winchesterb, N., Karplusb, V.J., Zhang, X., 2014. Will economic restructuring in China reduce trade-embodied $\mathrm{CO}_{2}$ emissions? Energy Econ. 42, 204-212.

Shui, B., Harriss, R.C., 2006. The role of $\mathrm{CO}_{2}$ embodiment in US-China trade. Energy Policy 34, 4063-4068.

$\mathrm{Su}, \mathrm{B} .$, Ang, B.W., 2010. Input-output analysis of $\mathrm{CO}_{2}$ emissions embodied in trade: the effects of spatial aggregation. Ecol. Econ. 70, 10-18.

Su, B., Ang, B.W., 2011. Multi-region input-output analysis of $\mathrm{CO}_{2}$ emissions embodied in trade: the feedback effects. Ecol. Econ. 71, 42-53.

Su, B., Ang, B.W., 2012. Structural decomposition analysis applied to energy and emissions: some methodological developments. Energy Econ. 34, 177-188.

$\mathrm{Su}, \mathrm{B} .$, Ang, B.W., 2013. Input-output analysis of $\mathrm{CO}_{2}$ emissions embodied in trade: competitive versus non-competitive imports. Energy Policy 56, 83-87.

Su, B., Ang, B.W., 2014. Input-output analysis of $\mathrm{CO}_{2}$ emissions embodied in trade: a multi-region model for China. Appl. Energy 114, 377-384.

Su, B., Huang, H.C., Ang, B.W., Zhou, P., 2010. Input-output analysis of $\mathrm{CO}_{2}$ emissions embodied in trade: the effects of sector aggregation. Energy Econ. 32 (1), 166-175.

Su, B., Ang, B.W., Low, M., 2013. Input-output analysis of $\mathrm{CO}_{2}$ emissions embodied in trade and the driving forces: processing and normal exports. Ecol. Econ. 88, 119-125.

United Nations, 1999. Handbook of input-output table compilation and analysis. Studies in Methods Series F No. 74. Handbook of National Accounting, United Nations.

Wang, T., Watson, J., 2007. Who owns China's carbon emissions. Tyndall Briefing Note No. 23.

Weber, C.L., Peters, G.P., Guan, D., Hubacek, K., 2008. The contribution of Chinese exports to climate change. Energy Policy 36, 3572-3577.

Weitzela, M. Ma, T., 2014. Emissions embodied in Chinese exports taking into account the special export structure of China. Energy Econ. 45, 45-52.

Yan, Y., Yang, L., 2010. China's foreign trade and climate change: a case study of $\mathrm{CO}_{2}$ emissions. Energy Policy 38 (1), 350-356.

$\mathrm{Yu}, \mathrm{H}$., 2012. The influential factors of China's regional energy intensity and its spatial linkages: 1988-2007. Energy Policy 45, 583-593.

Zhang, Y., 2012. Scale, Technique and composition effects in trade related carbon emissions in China. Environ. Resour. Econ. 51, 371-389.

Zhang, H., Lahr, M.L., 2014. China's energy consumption change from 1987 to 2007: a multi-regional structural decomposition analysis. Energy Policy 67, 682-693.

Zhang, Y., Qi, S., 2012. China's Multi-regional Input-output Models for 2002 and 2007. China Statistics Press, Beijing (in Chinese).

Zhang, J., Wei, W., 2011. Influence of international financial crisis on China's regional export: based on trade structure. J. Int. Trade 37 (2), 3-11 (in Chinese).

Zhang, Y., Zhang, J., Yang, Z., Li, S., 2011. Regional differences in the factors that influence China's energy-related carbon emissions, and potential mitigation strategies. Energy Policy 39, 7712-7718.

Zhong, W., Lin, J., 2012. Study on the effect of global financial crisis on China's export trade and countermeasures. J. Int. Trade 38 (9), 161-168 (in Chinese). 